REVIEW

\title{
Secondary transport of the critically ill and injured adult
}

\author{
A Gray, S Bush, S Whiteley
}

Emerg Med J 2004;21:281-285. doi: 10.1136/emj.2003.005975

There is significant interest in the secondary transport of the critically ill and injured. High profile cases entailing the long distance transfer of patients have highlighted the lack of availability of critical care beds and appropriate systems for transferring this patient group. These and other issues have culminated in the release of Comprehensive Critical Care by the Department of Health in 2000. It has been shown that a large number of critical care transfers originate in the emergency department. The transportation of patients has not traditionally been part of the core curriculum of emergency medicine specialists in the UK. It is imperative that clinicians have an understanding of the issues surrounding transportation of the critically ill and injured. This should include appreciation of the local and regional organisational frameworks implemented for this patient group. This review describes the core issues relevant to emergency medicine relating to the transportation of the critically ill and injured.

See end of article for authors' affiliations

Correspondence to: Mr A Gray, Emergency Department, Royal Infirmary of Edinburgh, Lauriston Place, Edinburgh EH3 9YW, UK; Alasdair. Gray@luht.scot.nhs.uk

Accepted for publication 29 September 2003
Cor n 2000, the Department of Health released Comprehensive Critical Care partly as a result of high profile cases involving the long distance of critically ill and injured patients. ${ }^{1}$ It has been shown that a large number of critical care transfers originate in the emergency department. ${ }^{2}$ Previous publications have estimated that 11000 critically ill and injured adult patients are transferred between hospitals in the United Kingdom each year. ${ }^{3}$ These figures are likely to be an underestimate as they reflect transfers between or into an intensive care unit (ICU) rather than the transfer of all critically ill or injured. Nationally, the numbers of critically ill and injured transferred from or into an emergency department (ED) is unknown although data from a regional study in Yorkshire ${ }^{2}$ suggest that it is a significant proportion of the total number of critically ill adults requiring secondary transport.

The transportation of patients can be divided into a number of specific categories: Primary transport (prehospital care) is the transfer of patients from site of illness or injury to first hospital contact. This is largely undertaken by paramedics in the UK. Primary transport is beyond the scope of this review and is well described in the emergency medicine literature. ${ }^{4-6}$ Secondary transport is the transfer of the patient from one hospital to another for continuing clinical care (interhospital transfer). This type of transfer may occur for a variety of clinical and non-clinical reasons. Intrahospital transport is the transfer of patients between departments within the same hospital, for example, from the ED to radiology suite or ICU. The hazards and care required during intrahospital transfer are identical to that required for secondary transport ${ }^{7-10}$ and will not be covered separately in this review.

The standards of care provided during transfer have been widely reported as frequently being suboptimal with a lack of monitoring and appropriately trained staff $^{31-14}$ leading to a significant number of adverse events in both adults and children. ${ }^{14-19}$ These findings resulted in professional organisations publishing guidelines on how the transfer of the critically ill should be conducted. ${ }^{20-26}$

Emergency medicine has a key part to play in the organisation of secondary transportation. The specialty has historically had strong links with prehospital care and emergency medical services (EMS). Recent data also suggest that the ED is the second most common department within the hospital to refer and to receive critically ill and injured adults (unpublished data, Alasdair Gray).

This review details the processes of care of the critically ill and injured adult during secondary transport emphasising current clinical and political issues specifically pertinent to the specialty of emergency medicine.

\section{INDICATIONS FOR TRANSFER}

Secondary transport should only occur if it is likely to improve the patient's clinical outcome. ${ }^{26}{ }^{27}$ It should be undertaken in a manner that does not jeopardise the level and quality of care being given. ${ }^{28} 29$

Table 1 lists the indications for the secondary transport of the critically ill adult. The foremost reason for transfer from the ED is a requirement for specialist care. This is often for neurosurgical care $^{23031}$ but includes patients with ruptured abdominal aortic aneurysm and other injured patients requiring specialist management (cardiothoracic, maxillofacial, orthopaedic, and burns). Another reason for transfer is for further investigations that are unavailable at the referring site such as angiography. Non-clinical transfers occur when a patient is transferred because of the lack of a critical care bed or insufficient staff capacity at the referring hospital. The decision to transfer a patient for a non-clinical reason can be extremely difficult as the risk of transfer to another hospital may exceed the anticipated benefits. ${ }^{26}$ Ideally, no patient should be transferred for non-clinical reasons. However, if necessary, the patient transferred should be normally the most "stable" 
critically ill patient in the hospital. Another factor, which may influence the decision, is the next of kin being required to travel long distances to be with the patient and the length of time that the person is likely to require critical care support. A final reason for transfer is for repatriation because the patient has become ill or injured in a different geographical area to their residence or because they were originally transferred away from their local hospital.

\section{MODE OF TRANSPORT}

The mode of transport ${ }^{26}$ used is dependent on the characteristics outlined in the box. Standard road ambulances undertake most of the transfers in the UK. Increasingly, local EMS services have specific vehicles designed for the secondary transport of the critically ill. These need to be accessible and have equipment familiar to the transferring staff. Air transport by helicopter is becoming more available but is not necessarily ideal if landing sites are not adjacent to the ED necessitating additional short distance ambulance transfers. Nevertheless, air transport should be considered if transfer distances greater than 80 kilometres or transfer times greater than 90 minutes are anticipated. ${ }^{26}{ }^{29}$ Irrespective of the mode of transport, but particularly with aeromedical transport, access to the patient is limited and therefore if the patient does deteriorate en route intervention may be difficult. ${ }^{26}$ The physiological response to air transportation and environmental factors such as noise and vibration also needs to be considered. ${ }^{31} 32$ Accompanying staff should be aware of the potential dangers of air transportation and have participated in specific aeromedical training.

\section{ACCOMPANYING STAFF}

About $90 \%$ of all secondary transports are undertaken by personnel from the referring hospital using their equipment and a standard ambulance. ${ }^{29}$ These medical and nursing staff are often not appropriately trained or experienced. ${ }^{3}{ }^{12-14}$

There is some evidence from the $\mathrm{UK}^{34} 38$ and other countries $^{39}$ that the quality of care is improved if a specialist retrieval or transfer team is used. It is however unproven as to whether this is attributable to availability of equipment, increased seniority or training of transport personnel, or better stabilisation that the team may perform before transfer. Retrieval teams are advocated by the Department of Health ${ }^{1}$ and some professional organisations. ${ }^{26}$ No clinical or cost effectiveness data are available for teams transporting adults when compared with standard care. More robust data are available for paediatric retrieval teams, which have been shown to be safer and more effective than standard care. ${ }^{4041}$ The Paediatric Intensive Care Society ${ }^{42}$ now recommends the use of paediatric retrieval teams. Emergency departments receiving children should be aware of local availability of a
Influencing factors on choice of transport

1 The nature of the illness

2 Urgency of transfer

3 Availability of transport

4 Mobilisation times

5 Geographical factors

6 Traffic and weather conditions

7 Cost

paediatric retrieval team and methods of team activation. Potential difficulties that need consideration include contingencies when the team is needed in two places simultaneously and how rapidly the transfer is required. The role of the team when they are not involved in patient transfer also needs to be defined. The optimal make up of these teams has not be delineated. In general, a senior middle grade doctor from anaesthesia or intensive care and at least one senior intensive care nurse in addition to the ambulance staff would constitute the team.

\section{TRAINING}

Comprehensive Critical Care $^{1}$ discusses the need to improve training in all aspects of critical care. There is, however, little structured training available either for medical or nursing staff on the process of transferring the critically ill and injured. Training courses such as the Safe Transfer and Retrieval (STaR) course $^{43}$ are run by the ALSG group have been developed recently. Increasingly, ED medical and nursing staff are involved in the transfer of critically ill patients. It is, therefore, imperative that they have the appropriate training.

\section{PRETRANSFER CARE}

All transfers require physiological stability for optimum patient outcome. ${ }^{26}{ }^{43-45}$ Physiological stability during the transfer mandates careful pretransfer assessment and optimisation of the patient. Missed or undertreated injuries, $^{16}{ }^{1746-48}$ neglected pretransfer respiratory or cardiovascular instability, ${ }^{16-18} 4647$ and lack of anticipation of potential events ${ }^{19} 43$ during the transfer can adversely affect outcome.

Patients who require resuscitation on arrival at the receiving hospital are likely to have a worse outcome and often should not have left the referring hospital without further treatment. Equally, delay in transfer may be detrimental to certain groups of patients, for example, intracranial

Table 1 Reasons for the secondary transport of the critically ill adult

\begin{tabular}{|c|c|}
\hline Reason for transfer & Definition \\
\hline No critical care facilities & $\begin{array}{l}\text { No critical care facilities on hospital site at any time, for example, } \\
\text { cottage or private hospital }\end{array}$ \\
\hline Investigation & $\begin{array}{l}\text { Need for specialist investigational facilities, for example, } \\
\text { angiography or referral centre (imaging?) diagnostic facilities } \\
\text { unavailable }\end{array}$ \\
\hline Absence of normal clinical expertise & $\begin{array}{l}\text { Normal medical expertise not available at referral site, usually } \\
\text { because of medical staff absence, for example, vascular surgeon on } \\
\text { holiday }\end{array}$ \\
\hline Specialist facilities & Medical expertise or therapeutic intervention \\
\hline Repatriation & $\begin{array}{l}\text { This can be local, regional, or international. Either because the } \\
\text { patient was originally transferred from their local hospital or because } \\
\text { they became ill at a remote site }\end{array}$ \\
\hline Non-clinical transfer & $\begin{array}{l}\text { Current unavailability of an appropriately staffed critical care bed at } \\
\text { referring site }\end{array}$ \\
\hline
\end{tabular}


haematomas ${ }^{49}{ }^{50}$ or ruptured abdominal aortic aneurysms. There is little evidence that other groups of patients are adversely affected by longer pretransfer times. ${ }^{51}{ }^{52}$ It is clear that time constraints should not affect the essential provision of physiological stability to the patient before transfer.

It is recommended that pretransfer assessment and stabilisation is approached using the ABCDE method (visit the journal web site to see details of the ABCDE method http://www.emjonline.com/supplemental).

\section{PREPARATION FOR TRANSPORT}

The ED must ensure appropriate preparation and packaging of the patient before transfer. Appropriate equipment, monitoring, and trained staff should be readily available. Patient assessment and packing should follow a system as already described. The return journey should be organised before leaving the hospital and transferring staff should have appropriate clothing, mobile telephone and money in case of emergencies. The accompanying staff, if from the referring hospital, should have ideally been involved in the patient's care since presentation. If this is not the case there should have been adequate hand over between staff before departure. The route to the hospital and access to the receiving department should be clearly defined. Relatives should be informed and provision made for their travel arrangements to the receiving hospital.

Accompanying medical and nursing staff should have appropriate levels of insurance cover. ${ }^{26}$

\section{CONSIDERATIONS DURING TRANSPORT}

If appropriate measures have been taken before transfer, there should be little requirement for active intervention during transport. Continued reassessment of the patient's clinical status during transfer is mandatory. Vascular access sites should remain accessible during transfer. Ideally, the level of monitoring and the frequency of measurement of physiological parameters should be the same as it would be in theatre or the resuscitation room. Vibration and vehicle movement may interfere with the monitoring. All equipment and monitoring should be adequately secured and staff seated and wearing seatbelts. Battery life of equipment should be long enough to cover the transfer time comfortably. If not spares should be carried or the compatibility with the ambulance power supply needs to be ensured. Additionally the difficulty with communication during transport between staff and patient especially during air transport needs to be considered. Adverse events should be recorded and action taken to resolve the problem as quickly as possible.

The use of "blue lights" and police escort should be restricted to situations that are completely necessary and not used routinely.

The ambulance should conform to the current CEN regulations (UK-BS EN 1789; 2000). This standard is currently voluntary and indicates the design, performance, and specification of the ambulance.

\section{POST-TRANSFER CARE}

The patient is the responsibility of the transferring team until formal nursing and medical handover has occurred in the receiving department. The patient should be received in a safe environment with the receiving team already assembled. If the patient has potential for instability or the management plan is unclear the patient should be received by the team in the ED resuscitation room. ${ }^{61}$ The patient should then be reassessed using the $\mathrm{ABC}$ method, monitoring and ventilators changed, and blood gas pressures rechecked. The patency and security of all lines, tubes, and drains should be re-evaluated. All relevant documentation should be handed over including blood results and radiographs. The receiving staff must be informed of issues relating to the patient's relatives. All equipment must be collected and return with the transferring staff.

\section{COMMUNICATION AND DOCUMENTATION}

Good communication between referring and receiving medical and nursing staff is imperative. Specific faxed transfer letters and teleradiology ${ }^{62}$ have been shown to be effective. A number of authorities have published pretransfer checklists, en route documentation, and transfer forms. These should include all pertinent clinical details including physiological status.

The ambulance service needs to be informed and an ambulance booked according to local policy.

The receiving hospital should be informed if there is any change in anticipated time of transfers or clinical status. The receiving hospital should be alerted when the patient leaves the referring hospital and 10 minutes before arrival.

Directions to the hospital and the department within the hospital need to be clear. The patient and relatives should be kept informed at all times. Relatives should not routinely travel with the patient.

\section{LOCAL AND REGIONAL ORGANISATION OF SECONDARY TRANSPORTATION}

The Department of Health report, Comprehensive Critical Care, ${ }^{1}$ outlines ways in which critical care should be delivered locally and regionally in England and Wales. This has implications for all EDs, as they are an integral part of each hospital's critical care facility. A regional system for the care of the critically ill and injured coordinated through the development of critical care networks is being implemented. These Critical Care Networks are responsible for developing guidelines and quality assurance programmes for the secondary transport of the critically ill and injured adult. They are also tasked with improving the training of staff involved in the transfer process. The principal objective of these developments is to improve and standardise clinical care across a defined geographical area by setting standards and developing quality assurance programmes.

The ED must be aware of contact numbers for their regional intensive care bed bureau and other members of the local transfer group. Local referral policies and guidelines and contacts for specialist services, for example, neurosurgery and burns and paediatric retrieval team would be useful.

Other initiatives that may have an impact on the number of secondary transports of critically injured patients from the ED include the recent publication by the Royal College of Surgeons of England and the British Orthopaedic Association $^{63}$ on the management of major trauma and head injuries. These documents advise that patients should be taken from the site of the accident to the most appropriate hospital not the nearest as has traditionally happened within the United Kingdom. This would result in a reduction in the number of secondary transfers, in particular, patients with significant head injuries.

Traditionally, critically ill patients have been transported from the referring to receiving hospital in an ad hoc manner. This has resulted in varied clinical practice and standards during the transport process (see pretransfer care). Comprehensive Critical Care ${ }^{1}$ explicitly supports local as well as regional coordination of the process. The level of care given to an individual patient will be consistent within a hospital and not dependent on their source department or the individual clinician involved. This will once again require the ED to be responsible with the rest of the hospital in developing a safe robust system for transferring patients from the ED to other hospitals and departments. There should be 
clear guidance as to who accompanies patients during transfer, in particular, the non-intubated but critically ill patient who have been shown to have a high critical incident rate.

\section{IMPLICATIONS FOR EMERGENCY MEDICINE}

This review highlights the central position of the ED in the process and organisation of the secondary transfer of the critically ill and injured and the delivery of critical care in the hospital. Recent proposals from the Department of Health and professional bodies suggest that our specialty will be increasingly involved in the development of transport systems and the Critical Care Networks associated with them. The specialty requires medical and nursing representation at local and network levels to address the issues that surround the transfer of the critically ill from the ED. Quality assurance systems are required to monitor processes and quality of care within the system. Adequate training is mandatory for ED medical and nursing staff accompanying critically ill patient during transfer. Consideration needs to be given to standardisation and the improvement in availability of transport equipment and monitoring in individual hospitals and across networks.

These changes need to be led and directed by the specialty in conjunction with, rather than be invoked by outside agencies and other specialties.

\section{ACKNOWLEDGEMENTS}

Colin Robertson and Mark Airey for their editorial advice.

\section{Contributors}

AG conceived the idea and formulated the review outline with SW and SB. AG, SW, and SB all contributed to the writing of the review. AG edited the manuscript and will act as guarantor.

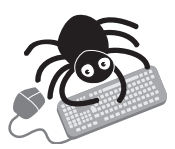

Details of the $A B C D E$ method are available on the journal web site (http://www.emjonline.com/ supplemental).

\section{Authors' affiliations}

A Gray, Emergency Department, Royal Infirmary of Edinburgh, Edinburgh, UK

S Bush, Emergency Department, St James's University Hospital, Leeds, UK

S Whiteley, Intensive Care Unit, St James's University Hospital

Funding: AG has received a regional health authorities research grant to study regional critical care transfers

Conflicts of interest: Simon Whiteley and Alasdair Gray prepared the current Intensive Care Society guidelines on the transport of the critically ill adult, on behalf of the council of the Intensive Care Society

\section{REFERENCES}

1 Department of Health. Comprehensive critical care. A review of adult critical care services. London: Department of Health, 2000.

2 Gray A, Gill S, Airey M, et al. Descriptive epidemiology of adult critical care transfers from the emergency department. Emerg Med J 2003;20:242-6.

3 Mackenzie PA, Smith EA, Wallace PGM. Transfer of adults between intensive care units in the UK. BMJ 1997:314:1455-6.

4 Coats TJ, Davies G. Prehospital care for road traffic accidents. BMJ 2002;324:1135-8.

5 Greaves I, Porter K, eds. Prehospital medicine: the principles and practice of immediate care. London: Arnold, 1999.

6 Tintinalli JE, Kelen GD, Stapczynski JS, eds. Emergency medicine. A comprehensive study guide. New York: McGraw and Hill, 2000.

7 Braman SS, Dunn SM, Amico CA, et al. Complications of intrahospital transport in critically ill patients. Ann Intern Med 1987;107:469-73.

8 Andrews PJD, Piper IR, Dearden NM, et al. Secondary insults during the intrahospital transport of head-injured patients. Lancet 1990;335:327-30.

9 Smith I, Fleming S, Cernaianu A. Mishaps during transport from the intensive care unit. Crit Care Med 1990;18:278-81.

10 Faculty of Intensive Care of the Australasian and New Zealand College of Anaesthetists, and Australian College of Emergency Medicine. Intra-hospital of critically ill patients. Melbourne: Australian and New Zealand College of Anaesthetists, 2000

11 Bion JF, Wilson IH, Taylor PA. Transporting critically ill patients by ambulance: audit by sickness scoring. BMJ 1988;296:170-1.

12 Wright IH, McDonald JC, Rogers PN, et al. Provision of facilities for secondary transport of seriously ill patients in the United Kingdom. BMJ 1988;296:543-5

13 Atkins ML, Pinder AJ, Murphy PG. Quality of care during the transfer of the critically ill neurosurgical patients in West Yorkshire: a comparison with national guidelines. J Neurosurg Anaesthesiol 1998;10:293

14 Vyvyan HAL, Kee S, Bristow A. A survey of secondary transfers of head injured patients in the south of England. Anaesthesia 1991;4:728-31.

15 Deane SA, Gaudry PL, Woods WPD, et al. Interhospital transfer in the management of acute trauma. Aust N Z J Surg 1990;60:441-6.

16 Gentleman D. Causes and effects of systemic complications among severely head injured patients transferred to a neurosurgical unit. Int Surg 1992;77:297-302

17 Hicks IR, Hedley RM, Razis P. Audit of transfer of head-injured patients to a stand-alone neurosurgical unit. Injury 1994;25:545-9.

18 Barry PW, Ralston C. Adverse events occurring during interhospital transfer of the critically ill. Arch Dis Child 1994;71:8-11.

19 Macartney I, Nightingale P. Transfer of the critically ill. Br J Anaesth CEPD reviews 2001;1:12-15.

20 American College of Emergency Physicians. Principles of appropriate patient transfer. Ann Emerg Med 1990; 19:337-8.

21 American College of Surgeons Committee on Trauma. Resources for the optimal care of the injured patient. Chicago: ACS, 1993.

22 Gentleman D, Dearden M, Midgley S, et al. Guidelines for resuscitation and transfer of patients with serious head injury. BMJ 1993;307:547-52.

23 Association of Anaesthetists of Great Britain and Ireland. Recommendations for the transfer of patients with acute head injuries to neurosurgical unit. London: AAGBI, 1996.

24 Guidelines committee of the American College of Critical Care Medicine. Guidelines for the transfer of critically ill patients. Crit Care Med 1993;21:931-7.

25 Faculty of Intensive Care of the Australasian and New Zealand College of Anaesthetists, and Australian College of Emergency Medicine. Minimum standards for transport of the critically ill. Melbourne: Faculty of Intensive Care of the Australasian and New Zealand College of Anaesthetists, and Australian College of Emergency Medicine, 1996

26 Whiteley S, Gray A, McHugh P, et al. On behalf of the Council of the Intensive Care Society. Guidelines for the transport of the critically ill adult. London: Intensive Care Society, 2002.

27 The Association of Anaesthetists of Great Britain and Ireland. Recommendations for standards of monitoring. London: The Association of Anaesthetists of Great Britain and Ireland, 2000.

28 Oakley PA. The needs for standards for inter-hospital transfer. Anaesthesia 1994;49:565-6.

29 Wallace PGM, Ridley SA. ABC of intensive care. Transport of critically ill patients. BMJ 1999:319:368-71.

30 Cooke RS, McNicholl BP, Byrnes DP. Early management of severe head injury in Northern Ireland. Injury 1994;26:395-7.

31 Grant PT, Shrouder S. Initial assessment and outcome of head injured patients transferred to a regional neurosurgical service: what do we miss? J Accid Emerg Med 1997;14:10-12.

32 Webb AR, Shapiro MJ, Singer M, et al, eds. Oxford textbook of critical care. Oxford: Oxford University Press, 1999.

33 Oh TE, ed. Intensive care manual. London: Butterworths, 1998.

34 Reeve WG, Runcie CJ, Reidy J, et al. Current practice in transferring critically ill patients among hospitals in the west of Scotland. BMJ 1990;300:85-7.

35 Runcie CJ, Reeve WR, Wallace PGM. Preparation of the critically ill for interhospital transfer. Anaesthesia 47:327-31.

36 McGinn GH, Mackenzie RE, Donnelly JA, et al. Interhospital transfer of the critically ill trauma patient: the potential role of a specialist transport team in a trauma system. J Accid Emerg Med 1996;13:90-2.

37 Bannell KJ, Fielden JM, Taylor BL, et al. Specialist transfer teams can operate effectively from district general hospitals. BMJ 1997:315:605.

38 Bellingham G, Olivier T, Batson S, et al. Comparison of a specialist retrieval team with current United Kingdom practice for the transport of critically ill patients. Intensive Care Med 2000;26:740-4.

39 Ehrenworth J, Sorbo S, Hackel A. Transport of critically ill patients. Crit Care Med 1986;14:543-7.

40 Edge WE, Kanter R, Weigle GM, et al. Reduction of morbidity in interhospital transport by specialized pediatric staff. Crit Care Med 1994;22:1 186-91.

41 Britto J, Nadel S, Maconochie I, et al. Morbidity and severity of illness during interhospital transfer: impact of a specialised paediatric team. BMJ 1995:311:836-9.

42 Paediatric Intensive Care Society. Standards for paediatric intensive care, including standards of practice for the transport of the critically ill child. London: PICS, 1996.

43 Advanced Life Support Group. Safe transfer and retrieval. The practical approach. London: BMJ Books, 2002.

44 Ridley SA, Wright IH, Rogers PN. Secondary transport of critically ill patients. Hospital Úpdate 1990:289-300

45 Runcie CJ, Reeve W, Reidy J, et al. Secondary transport of the critically ill adult. Clin Intensive Care 1991;2:217-25.

46 Henderson A, Coyne T, Wall D, et al. A survey of interhospital transfer of head-injured patients with inadequately treated life-threatening extracranial injuries. Aust N Z J Surg 1992;62:759-62.

47 Gentleman D, Jennet B. Audit of transfer of unconscious head-injured patients to a neurosurgical unit. Lancet 1990;335:330-4. 
48 Dunn LT. Secondary insults during the interhospital transfer of head-injured patients: an audit of transfers in the Mersey Region. Injury 1997;28:427-31

49 Mendelow AD, Karmi MZ, Paul KS, et al. Extradural haematoma: effect of delayed treatment. BMJ 1979;1:1240-2.

50 Seelig JM, Becker DP, Miller JD, et al. Traumatic acute subdural haematoma: major mortality reduction in comatose patients treated within four hours. N Engl J Med 1981;304:1511-18.

51 Kearney PA, Terry L, Burney RE. Outcome of patients with blunt trauma transferred after a diagnostic or treatment procedure or a four-hour delay. Ann Emerg Med 1991;20:883-6.

52 Veenema KR, Rodewald LE. Stabilization of rural multiple-trauma patients at level III emergency departments before transfer to a level I regional trauma center. Ann Emerg Med 1995;25:175-81.

53 Walls RM, Luten RC, Murphy MF, et al, eds. Manual of emergency airway management. Philadelphia: Lippincott, Williams and Wilkins, 2000.

54 American College of Surgeons. Advanced trauma life support manual. Chicago: ACS, 1997.

55 Gervais HW, Eberle B, Konietzke D, et al. Comparison of blood gases of ventilated patients during transport. Crit Care Med 1987; 15:761-3.
56 Waddell G, Scott PDR, Lees NW, et al. Effects of ambulance transport in critically ill patients. BMJ 1975;1:386-9.

57 Ridley S, Carter R. The effects of secondary transport on critically ill patients. Anaesthesia 1989:44:822-7.

58 Runcie CJ, Reeve WG, Reidy J, et al. Blood pressure measurement during transport. A comparison of direct and oscillometric readings in critically ill patients. Anaesthesia 1992;45:659-65.

59 Hauswald M, McNally T. Confusing extrication with immobilization: the inappropriate use of hard spine boards for interhospital transfers. Air Medical Journal 2000;19:126-7.

60 Steedman DJ. Hypothermia. In: Environmental medical emergencies. Oxford: Oxford University Press, 1997

61 O'Connor PM, Steele JA, Dearden CH, et al. The accident and emergency department as a single portal of entry of all trauma patients to transferred to specialist units. J Accid Emerg Med 1996;13:9-10.

62 Goh KY, Lam CK, Poon WS. The impact of teleradiology on the inter-hospital transfer of neurosurgical patients. Br J Neurosurg 1997;11:52-6.

63 A Joint Report from the Royal College of Surgeons of England and the British Orthopaedic Association. Better care for the severely injured. London: RCSE/ BOA, 2000. 